\title{
Siempre nos quedará Bourdieu- Luis Enrique Alonso (Ed.) Círculo de Bellas Artes, Madrid, 2021
}

\author{
Adrián Espada Benito \\ Universidad Autónoma de Madrid, España. \\ adryesbe@gmail.com
}

De reciente publicación por el Círculo de Bellas Artes (CBA), esta obra, que edita Luis Enrique Alonso Benito, es el resultado de compilar las intervenciones realizadas durante unas jornadas tituladas El oficio de sociólogo. El legado de Pierre Bourdieu que fueron llevadas a cabo en el año 2012. Éstas servían de complemento y, por así decir, de refuerzo teórico, a la exposición Imágenes de Argelia que, igual que las jornadas, se realizó en el CBA. En esta exposición se ofrecían al público las fotografías que Pierre Bourdieu fue realizando durante su estancia argelina en torno a los años cincuenta del pasado siglo. Como recuerda su editor en el prefacio al libro (p. 13), estas imágenes, que son de un gran valor doxográfico y sociológico y que están accesibles en la web del Círculo, fueron incluidas en un catálogo del mismo cuyo contenido "tendía a coincidir con la edición original del libro Images d'Algérie, une affinité élective". Su gran valor reside en abrir una ventana a la época argelina en la que Bourdieu comienza a configuar su plataforma sociológica, es decir, a una parte muy importante en la génesis de su pensamiento.

Son, justamente, estos dos niveles, presentes en tales catálogos, los que determinan los ejes sobre los cuales pivotaron las conferencias y el libro que nace de ellas: por un lado, el desgranamiento crítico de la relación Bourdieu-Argelia, por el otro, la concepción sociológica bourdiana y sus principales aportes y vínculos con la teoría sociológica contemporánea. En este sentido, la obra se estructura en torno a nueve textos, dos de ellos, el de Cecilia Flachsland (sobre la figura de Eva Perón a la luz de las aportaciones bourdianas) y el de Marina Requena-i-Mora (sobre el fetichismo de la conciencia medioambiental y el "ecologismo popular"), fueron añadidos expresamente para esta edición a las intervenciones que aparecieron en el congreso. Hay, por tanto, una suerte de organización temática bimembre presente en este libro, que le da coherencia y lo estructura.

En primer lugar, los textos orientados a la reflexión en torno a Bourdieu y Argelia, entre los cuales se inscribe el texto de Lahouardi Addi, Pierre Bourdieu, Argelia y el pesimismo antropológico, que, al par que reconstruye ciertas partes del decurso biográfico de Bourdieu, tiene la destacable virtud de ir indagando y presentando, desde ello, toda una serie de supuestos antropológico-filosóficos implicados, no sólo en la teorización bourdiana de lo social, sino en su trayectoria misma de compromisos con el mundo político y en su forma de entender la relación que ha de 
tener el ejercicio sociológico con un tal ámbito. En este texto, se nos presenta a un Bourdieu, a la vez, comprometido con la capacidad crítica de la sociología (entendida como un contrapoder capaz de deslegitimar las arbitrariedades naturalizadas, que serían resultado, al tiempo que medio de reproducción, de las formas de violencia y dominación simbólica) y desengañado respecto a las formas de illusio, de implicación afectiva e imaginaria que articulan el mundo social ( $y$, desde luego, también el político): de ahí vendría su, nunca ingenuo ni pasivo, "pesimismo antropológico".

En esta misma línea se sitúan también los textos de Aïssa Kadri, Pierre Bourdieu. La época de Argelia, y de Enrique Martín Criado, Bourdieu y Argelia: una sociología combativa. Ambos textos son muy afines, y cierran el grupo de las intervenciones dedicadas a ahondar en la relación Bourdieu-Argelia. Sin embargo, tal afinidad, que a veces supone una cierta reiteración en el tratamiento y reconstrucción de los hechos, no nubla la diferencia que está presente en sus aportaciones. En ambas se reconstruye, en detalle, la experiencia argelina bourdiana, mostrando su complejidad, sus dificultades y tensiones. Nos presentan a un joven Bourdieu que, tras realizar sus estudios filosóficos y salir de la École Normale Supérieure (ENS), va progresivamente internándose en el campo sociológico-antropológico a través de un reclutamiento militar en el cual queda al cargo de realizar una aproximación científico-social a una Argelia que empieza a luchar por desembarazarse de su situación colonial respecto a Francia.

Una aportación muy valiosa e interesante del texto de Kadri es el capítulo titulado "Regreso a Argelia", que remite a su testimonio personal de aquellos momentos, derivado de una experiencia de investigación y tesis de tercer grado, dirigida por Jean-Claude Passeron, en torno a 1967, que le permitió vivirlos en primera persona. Respecto al texto de Martín Criado, cabe destacar la precisa contextualización que se hace del periodo bélico (y prebélico), la cual arroja mucha luz sobre las cuestiones tratadas, al permitir entender con mayor claridad, como dice su autor, las "apuestas políticas" que había tras los primeros libros de Bourdieu. Tal aportación, al mismo tiempo, nos permite "persuadirnos" mejor del sentido de un tópico bourdiano, que aparece en forma de cita a Passeron al final de la intervención de Kadri (p. 156): "el Bourdieu sociólogo quería persuadirme de que el conocimiento científico podría suministrar, por su propia virtud, una justificación para un No lanzado contra todos 'los poderosos de este mundo'”.

Este "tópico" queda perfectamente sintetizado en el título de una recopilación de intervenciones que organizó Jacques Bouveresse, una suerte de in memoriam colectivo, que es citada por Luis Enrique Alonso: La liberté par la connaissance. Este lema, de raigambre estoica y presente quizá en Bourdieu más bien vía Spinoza, hace emerger, de nuevo, ese carácter intrínsecamente implicado que la teoría tiene con lo político. Alonso, hacia el final de su texto, homónimo al libro y ubicable ya en la parte teórica del mismo, lo expresa del siguiente modo (p. 89): “Siempre nos quedará Bourdieu porque es el mayor exponente de una tradición de la sociología que une el racionalismo de la investigación rigurosa del sistema de relaciones sociales con una inquietud permanente por las consecuencias legitimadoras (o potencialmente deslegitimadoras) de las prácticas que fundamentan el conocimiento en el que se desenvuelven los actores". Sobre el lugar y vínculos de Bourdieu con esta "tradición sociológica" nos habla Alonso a lo largo de su texto, indicando, con erudita precisión y riqueza, la trama de relaciones (tan abundante en continuidades como en discontinuidades) que unen al sociólogo francés con la misma: sus relaciones con clásicos de la sociología como Marx, Weber, Veblen, Elías, Durkheim, Mauss; su interesantísima, y menos habitualmente destacada, relación con Edmond Goblot en torno al tan importante concepto de distinción; su distancia y resistencia frente a ciertas derivas contemporáneas que, presentes dentro y fuera del campo sociológico, tienden a disolver el alcance y potencia del razonamiento y la mirada sociológica... 
Por ello, Siempre nos quedará Bourdieu es el título del libro que aquí reseñamos, pero es también, y más sustancialmente, una proclamación sociológica de primer orden: la de que la sociología siempre podrá contar con el asidero bourdiano, no como un refugio escolástico o dogmático, sino como un acicate para la comprensión rigurosa de lo social que se presenta bajo forma de legado: el de un herramental teórico-conceptual desde el que el análisis y la problematización de las realidades empírico-sociales puede llegar a buen puerto y reivindicar su inmanencia categorial.

Muy próximas a estos problemas están las reflexiones que comparte José Luis Moreno Pestaña en su texto: Sobre la actualidad de "El oficio de sociólogo". En él, se plantean cuestiones epistemológicas de gran importancia, recuperando obras como la que aparece en el título y otras, igualmente relevantes y célebres, como El razonamiento sociológico de Jean-Claude Passeron. En su texto, se nos propone una sociología configurada en torno a tres principios que permitirían a la sociología, si no avanzar, al menos no retroceder: 1. de discontinuidad, que produce el pensamiento científico riguroso cuando, distanciándose de las doxas, se realizan esfuerzos tales como el de la determinación de modelos analíticos o el de la construcción vigilante y reflexiva del objeto de estudio (algo que es un antiguo motivo filosófico -ya Platón trataba la diferencia entre "géneros de conocimiento" en La repúblicapero que, contemporáneamente, se inscribe como tema fundamental de la filosofía bachelardiana); 2 . de opacidad, que alerta respecto del decalaje existente entre el sentido objetivo y subjetivo de un acto, esa "heterogonía de los fines", en términos de W. Wundt, que es vinculable también a Pareto o R. Aron; 3. de autonomía, que, siguiendo la estela de la reivindicación weberiana, mantiene la necesidad de explicar lo social por lo social o, como dice el autor del texto (p. 224), de producir una "sociología que trabaje desde sus reglas de argumentación, desde la modestia de sus artesanales técnicas y sus tradiciones teóricas". Moreno Pestaña añade a estos, junto a Passeron, un cuarto principio, "franciscano", que supone "la conciencia de que todo enunciado empírico tiene un sentido teórico infradeteminado por los enunciados observacionales" (p. 226).

De este bloque temático forma también parte la intervención de Ildefonso Marqués Perales, El "habitus". Un nuevo uso para un nuevo útil, que, centrado en este importantísimo concepto bourdiano, nos muestra los vínculos teóricos que están tras él: su relación con Mauss, Husserl, Marx, Pascal... o con el tomismo, conexión menos habitualmente resaltada y que, según Marqués (p. 166), responde a que "Bourdieu, en la École Normale Supérieure (ENS), no se había relacionado con la gente del partido comunista, sino con grupos católicos, y al hecho de que hubiera tomado mucho de la filosofía tomista". Como vemos, el vínculo de la sociología de Bourdieu con la filosofía es algo que, como un bajo continuo, aparece constantemente (en unas y otras formas) a lo largo del libro. Compartimos, en todo caso, la conclusión de su autor respecto a la vigencia y la relevancia del concepto de habitus. Concepto que, de forja crítico-dialéctica, aspira a superar manidas dicotomías que impiden el pensamiento sociológico, haciendo así más comprensiva su mirada.

En este último bloque, más teórico, frente al otro, más biográfico, incluiríamos también los dos textos que, al comienzo de esta reseña, habíamos indicado que se añadieron ex professo de la edición de este libro. Su justificación es la siguiente: en ellos vemos a un Bourdieu "ejercido" (actu exercito, en lenguaje escolástico), frente al Bourdieu "representado" (actu signato) que aparecía en los otros textos de este "bloque teórico". En los primeros, el herramental de Bourdieu está puesto en práctica, mostrándonos, de forma tan clara como sugerente (y dentro de los límites que el contexto discursivo en el que se inscriben permite), la vigencia y la capacidad analítica que tienen aún las categorías elaboradas por el sociólogo francés.

Cecilia Flachsland se centra en la obra La dominación masculina para, sin dejar de ser consciente de sus limitaciones y, de hecho, haciéndonoslas ver, reivindicar, por la 
vía del análisis, sus potencias a la hora de aproximarse a la figura de Eva Perón desde un ángulo que queda, de habitual, obliterado por los diferentes acercamientos que a ella se realizan. Nos muestra cómo, desde el prisma bourdiano, Eva Perón puede ser aprehendida como una importante figura política, en especial dentro del panorama feminista argentino, dado que, como recuerda Flachsland (p. 103), sus esfuerzos fueron fundamentales en la génesis de una "experiencia de "feminismo" plebeyo que desafió la dominación masculina, tanto entre los detractores del peronismo como en las filas del espacio político propio". Atender a esto, calzándose los anteojos bourdianos, que están detrás del interesante concepto de "plebiyismo de género" que propone la autora, es oponerse a una negación dominante, produciendo resonancias simultáneamente teóricas y ético-políticas. Afirma Flachsland, al final del texto ( $p$. 122-123), que, si bien, "la memoria trae muchas Evas posibles (...) hay una de ellas que es negada sistemáticamente: la mujer que construyó poder, la que logró armar un partido femenino propio". Recuperar aquí a Bourdieu, o, mejor, como decíamos, ejercerlo, es hacer frente, por la teoría, a un ejercicio de dominación masculina, y hacer de la comprensión un ejercicio político de resistencia:

“lo que el 'plebiyismo de género' sacudió en la dominación masculina fue repuesto de un modo dominante y estructural en la memoria, a través de la violencia de un golpe de Estado, pero también mediante las invariantes de los hilos de la dominación masculina y de la violencia simbólica" (p. 123).

Por último, encontraríamos la excelente aportación de Marina Requena-i-Mora, Del fetichismo de la conciencia medioambiental al "habitus" y las lógicas prácticas: el ecologismo de los pueblos, texto que, entre otras cosas, tiene la relevancia diferencial de incluir diversas aportaciones empíricas en su curso argumentativo. Entre ellas, algunas, como las informaciones provenientes de entrevistas, realizadas en el contexto de un trabajo de campo ligado a su tesis doctoral. Aquí ya vemos activo un principio fundamental de la sociología bourdiana: aquel que exige que la producción conceptual esté siempre vinculada a la investigación empírica -en tal relación (virtuosamente circular) consistiría lo fundamental del proceso de investigación social-. Hay, además, otra característica de este texto que lo vincula directamente a un gesto sociológico que permitiría ubicarlo tras la égida bourdiana: en la aportación de Requena-i-Mora, encontramos una cierta forma de "destrucción" del sentido común ecologista. Por decirlo siguiendo la expresión nietzscheana (que da continuidad metaforológica a la doble analogía del concepto como herramienta y de la sociología como oficio), hay una sociologización de la conciencia ecologista realizada "a martillazos", es decir, críticamente (mediante un krinein o separación de lo que se encuentra confuso). Esto se realiza mostrando que hay un malentendido que atraviesa la conceptualización de (y en) la conciencia medioambiental. La autora lo sintetiza perfectamente al final de su texto (p. 259):

Lo que es, de hecho, una relación social entre el crecimiento económico y el impacto ambiental asume la forma fantasmagórica de una relación entre un tipo de conciencia ambiental y los efectos que genera en el medioambiente, como el consumismo verde. Esta conciencia posmaterialista no tiene absolutamente ninguna conexión con el entorno físico y con las relaciones materiales que surgen de él y aliena los efectos que el crecimiento económico y la modernización están causando en el medioambiente.

Frente a ello, y al hilo de los trabajos de investigación realizados, la autora se percata de que "el comportamiento medioambiental de los pueblos estudiados aparece como un legado de la forma de vida de los antepasados, relacionado con un tipo de identidad derivada de estar socializado acorde con el propio ecosistema". Esta es la enseñanza proveniente del "ecologismo de los pueblos" que Requena-iMora reivindica, y que ahonda en las inextricables conexiones entre lo teórico y lo ético-político que hemos ido señalando constantemente en la reseña del libro. 
Cerraremos la misma con un eco de ecos, con unas palabras de Requena-i-Mora (p. 260), que estarían citando, y, con ello, recordando, a la tan destacable como valiosa figura de la sociología española que fue Jesús Ibáñez: “Frente a esta forma evidente de alienación de la memoria, proponemos 'la anamnesis histórica y biográfica, que significa recuperar la memoria histórica' y es una 'condición para el desbloqueo' de la situación actual". Palabras que, igualmente, se podrían decir respecto al "siempre quedará" que marca al libro, a la anamnesis de Bourdieu. Su figura permanece como "héritage d’insoumission", que diría É. Louis, como espuela ante las derivas sedantes de la razón sociológica y como plataforma galeata frente a las fuerzas que intentan disolver el pensamiento crítico y riguroso (¿no son lo mismo?) de lo social, y con él, a las maneras de resistencia que este permite articular. 